\title{
Determination of optimum operating conditions for production of polyhydroxybutyrate by activated sludge submitted to dynamic feeding regime
}

\begin{abstract}
QU Bo, LIU JunXin ${ }^{\dagger}$
State key Laboratory of Environment Aquatic Chemistry, Research Center for Eco-Environmental Sciences, Chinese Academy of Sciences, P.O. Box 2871, Beijing 100085, China

Polyhydroxybutyrate (PHB) was produced by activated sludge in a two-stage process. In the first stage, the sludge with high storage potential was enriched in a sequencing batch reactor (SBR) operated by a dynamic feeding regime. The biosynthesis of PHB was sequentially accomplished in a batch reactor in the second stage. This article focused on the optimization of PHB content by evaluating the effects of three critical factors: Dissolved oxygen, $\mathrm{pH}$ and food-to-microorganism (F/M) ratio in the batch reactor. The results showed that the rate of substrate uptake, as well as the yield and content of PHB increased with the increase of dissolved oxygen concentration. The control of $\mathrm{pH}$ was not necessary under the weak alkaline condition for improvement of PHB content, except for the case in which the pH value was out of rang of 7.0 to 10.0. The enhanced F/M ratio favored PHB accumulation in the range of 1.0 to 4.5 C-mmol/C-mmol and the highest PHB content, 64\%, was achieved at 4.5 C-mmol/C-mmol. When F/M ratio was enhanced to $6.0 \mathrm{C}$-mmol/C-mmol, the phenomenon of utilizing simultaneously intracellular PHB and external substrate by sludge was observed, which resulted in a sharp decrease of PHB content. The microscopic observation clearly confirmed that dynamic feeding regime was effective for selecting and enriching the sludge with a high storage potential.
\end{abstract}

polyhydroxybutyrate, activated sludge, dynamic feeding regime, optimum operating conditions

Conventional plastics have faced some severe problems, because of their persistency in the environment and non-biodegradability. Therefore, the biodegradable plastic has potentials in applications. Polyhydroxyalkanoates (PHAs) are the polyester of hydroxyalkanoates synthesized by numerous bacteria as intracellular carbon and energy storage compounds, and have similar mechanical properties to conventional plastics like polypropylene or polyethylene. Additionally, PHAs have the attractive features of being completely biodegradable, biocompatible, and produced from renewable sources. Polyhydroxybutyrate (PHB) is the most common and best characterized PHAs. For the economical production of PHAs, various bacterial strains, either wild-type or recombinant, and new fermentation strategies were developed with high content and productivity of PHAs ${ }^{[1,2]}$.
However, the PHAs production cost is still 8 to10 times more than that of conventional plastics. The major costs consist in the cost of pure culture fermentation and expensive pure substrates ${ }^{[3]}$. Recently, the production of PHB by activated sludge from the wastewater treatment plants has attracted attention ${ }^{[4-7]}$. The activated sludge can use cheap substrates (such as organic waste) and avoid the need of sterilization. Thus, the costs may be substantially reduced.

In wastewater treatment process, the microorganisms in activated sludge can often readily transform biodegradable carbon source into PHA before using them for

Received March 5, 2008; accepted June 2, 2008

doi: 10.1007/s11434-008-0566-0

'Corresponding author (email: jxliu@rcees.ac.cn)

Supported by National Natural Science Foundation of China (Grant No. 50621804) 
growth $^{[8-11]}$. Hence, it is feasible to transfer activated sludge to PHA producer through appropriate process modification. The dynamic feeding regime (feast-famine regime) has been employed to select and enrich the microorganisms with high PHB accumulation ability in a sequencing batch reactor(SBR), and is believed to be the most promising process for industrial production of PHB by activated sludge ${ }^{[5,12]}$. In the "feast" phase, a high organic loading provides an advantage for PHB storage in the microorganisms. In the "famine" phase without external substrate, the PHB in the microorganisms will be degraded for growth and energy production. Based on this consideration, a new two-stage process was proposed for PHB production by activated sludge ${ }^{[13,14]}$. In this two-stage process, the SBR and batch reactor are used in the first and second stages respectively. The SBR can enrich sludge with high storage potential by dynamic feeding. The sludge harvested from the SBR, at the end of a cycle, is put into the batch reactor, which is operated at a high organic load to saturate the storage potential. The PHB-rich sludge then flows to the downstream processes for extraction of PHB. The typical PHB content obtained by pure culture and activated sludge in literatures were listed in Table 1 . However, by now few works has been focused on the optimization of process parameters for improving PHB production.

In this study, the effects of three critical parameters, dissolved oxygen (DO) concentration, $\mathrm{pH}$ value and food-to-microorganism $(\mathrm{F} / \mathrm{M})$ ratio, were evaluated to improve the PHB content by optimizing the process operating conditions. Moreover, the nutrient elements, such as nitrogen and phosphorous, were sufficient in synthetic medium in this experiment. It is significant for PHB production by activated sludge with recoverable organic waste.

\section{Materials and methods}

\subsection{SBR set-up and operation}

The experimental setup of a SBR with a working volume of 2.0 L was used for selection and enrichment of sludge with a high storage potential. The SBR was operated with a cycle of $6 \mathrm{~h}$ consisting of $300 \mathrm{~min}$ of aerobic reaction, 10 min of settling, 3 min of effluent withdrawal and $47 \mathrm{~min}$ of idle. During the initial $10 \mathrm{~min}$ of aerobic reaction, $1.0 \mathrm{~L}$ fresh medium was pumped into the reactor by a peristaltic pump. The sludge retention time (SRT) was maintained in 6 days by mixed liquor withdrawal from the reactor once every cycle. The effluent was withdrawn in the middle of the reactor, leaving a working volume of $1 \mathrm{~L}$ at the beginning of the next cycle, which resulted in a hydraulic retention time (HRT) of $12 \mathrm{~h}$. Oxygen was supplied by an air compressor, and the DO concentration was always above $40 \%$ of the saturation value. The temperature was maintained at $(25 \pm 0.5)^{\circ} \mathrm{C}$ by using a water jacket and a thermostat bath. $\mathrm{DO}$ and $\mathrm{pH}$ were continuously monitored on-line. The SBR was operated without $\mathrm{pH}$ control.

The SBR was inoculated with activated sludge from a municipal wastewater treatment plant in Beijing, and the initial biomass concentration in the reactor was $2000 \mathrm{mg}$ MLSS /L. After the experimental startup, the SBR was monitored and sampled at regular intervals. The batch tests for PHB storage were performed after the steady-state in the SBR was reached. The criterion of the steady state was that a constant biomass concentration in the SBR was maintained over 7 days, and the dynamic pattern in $\mathrm{DO}$ and $\mathrm{pH}$ during one cycle did not change.

\subsection{Batch experiments}

Batch experiments were performed to investigate the effects of $\mathrm{DO}, \mathrm{pH}$ and $\mathrm{F} / \mathrm{M}$ ratio on the PHB storage.

Table 1 The results of PHB production in literatures

\begin{tabular}{|c|c|c|c|c|}
\hline Microorganisms & Carbon source & Process & PHB (\%) & References \\
\hline A. latus & Sucrose & Nitrogen limitation & 50 & [15] \\
\hline A. eutrophus & Glucose & Phosphorus limitation & 82 & [16] \\
\hline$R$. eutropha & VFA & Nitrogen limitation & 60 & [17] \\
\hline Recombinant $R$ eutropha & Soybean oil & no & 57 & [18] \\
\hline Recombinant E. coli & Glucose & no & 77 & [19] \\
\hline Activated sludge & VFA & no & 50 & [14] \\
\hline
\end{tabular}


For each test, the batch reactor with a volume of $400 \mathrm{~mL}$ was inoculated with biomass from the SBR collected at the end of cycle, to the chosen concentration (1000 mg MLVSS/L) by using the same medium of the SBR (without acetate and ammonia). At the beginning of tests, a concentrated solution including acetate and ammonia was fed with a pulse in the batch reactor to provide carbon source and nitrogen with pre-selected concentration. Aerobic reaction was followed to the end of storage reaction indicated by DO concentration increase suddenly.

Oxygen was supplied by an air compressor through a ceramic disperser inside the batch reactor. The airflow rate was measured and controlled by an airflow meter to maintain pre-selected DO concentration in reactor. The $\mathrm{pH}$ value in the reactor was not controlled, except for the experiments where the effect of $\mathrm{pH}$ was investigated. A $\mathrm{pH}$ auto-controller was used to keep $\mathrm{pH}$ at a pre-selected value by addition of $1 \mathrm{M} \mathrm{HCl}$ or $1 \mathrm{M} \mathrm{NaOH}$. Oxygen uptake rates (OUR) were determined on line by a respirometer as described by Smolders et al. ${ }^{[20]}$. DO and $\mathrm{pH}$ were continuously on-line monitored. The temperature and stirring rate were the same to those in SBR. The biomass in the batch reactor was sampled at regular intervals for analytical determination of acetate, PHB, and ammonia.

\subsection{Medium}

The culture medium used in this study was composed of (per liter of distilled water) $2460 \mathrm{mg} \mathrm{CH}_{3} \mathrm{COONa}(60$ C-mmol), $321 \mathrm{mg} \mathrm{NH}_{4} \mathrm{Cl}$ (6 N-mmol), $100 \mathrm{mg} \mathrm{MgSO}_{4}$, $20 \mathrm{mg}$ EDTA, $160 \mathrm{mg} \mathrm{K}{ }_{2} \mathrm{HPO}_{4}, 38 \mathrm{mg} \mathrm{KH} \mathrm{PO}_{4}, 70 \mathrm{mg}$ $\mathrm{CaCl} \cdot 2 \mathrm{H}_{2} \mathrm{O}, 20 \mathrm{mg}$ yeast extract and $2 \mathrm{ml}$ of trace elements solution. The trace elements solution consisted of (per liter of distilled water) $1500 \mathrm{mg} \mathrm{FeCl} \cdot 6 \mathrm{H}_{2} \mathrm{O}, 150$ $\mathrm{mg} \mathrm{H}_{3} \mathrm{BO}_{3}, 150 \mathrm{mg} \mathrm{CoCl} \cdot 6 \mathrm{H}_{2} \mathrm{O}, 120 \mathrm{mg} \mathrm{MnCl}_{2} \cdot 4 \mathrm{H}_{2} \mathrm{O}$, $120 \mathrm{mg} \mathrm{ZnSO}_{4} \cdot 7 \mathrm{H}_{2} \mathrm{O}$, $120 \mathrm{mg} \mathrm{KI}, 60 \mathrm{mg} \mathrm{Na} \mathrm{MoO}_{4}$. $2 \mathrm{H}_{2} \mathrm{O}, 60 \mathrm{mg} \mathrm{NiCl}, 30 \mathrm{mg} \mathrm{CuSO} \cdot 5 \mathrm{H}_{2} \mathrm{O}$. Thiourea $(20$ $\mathrm{mg} / \mathrm{L}$ ) was also added to inhibit nitrification, and then ammonia consumption was related to active biomass formation. In batch experiments, the mineral medium was the same to that used in SBR except for acetate and ammonia.

\subsection{Analytical procedure}

Mixed liquor suspended solids (MLSS), mixed liquor volatile suspended solids (MLVSS), specific oxygen uptake rates (SOUR) and ammonia were determined by using standard methods ${ }^{[21]}$. PHB and acetate were also determined during the experimental operation. $5 \mathrm{ml}$ of the mixture liquor was treated immediately after sampling with $6 \mathrm{M} \mathrm{HCl}$ solution, and the mixture was centrifuged at $10000 \mathrm{rpm}$ for $15 \mathrm{~min}$. The pellet obtained was lyophilized for PHB determination. The supernatant was filtered with $0.22 \mu \mathrm{m}$ membrane for acetate and ammonia determination. PHB was extracted, hydrolyzed, and esterified to 3-hydroxyacyl methyl esters, determined by gas chromatography (Angilent, 6890 NT with autoinjector 7683B), equipped with a $30 \mathrm{~m} \times 0.32 \mathrm{~mm} \times$ $0.25 \mu \mathrm{m}$ capillary column (HP-5, Angilent $)^{[22,23]}$. The acetate was determined by using the same gas chromatography with FID detector and a $30 \mathrm{~m} \times 0.32 \mathrm{~mm} \times$ $0.50 \mu \mathrm{m}$ capillary column (DB-FFAP, Angilent). The temperatures of the injector and detector were $240^{\circ} \mathrm{C}$ and $280^{\circ} \mathrm{C}$, respectively. The initial oven temperature was $70^{\circ} \mathrm{C}$ for $3 \mathrm{~min}$ followed by a ramp of $20^{\circ} \mathrm{C}$ per min for $5.5 \mathrm{~min}$ and a final temperature of $180^{\circ} \mathrm{C}$ for $3 \mathrm{~min}$. Nitrogen was used as the carrier gas with a flow rate of $2.6 \mathrm{~mL} / \mathrm{min}$. The detectable level was $1 \mathrm{mg} / \mathrm{L}$ for acetate.

\subsection{Microscopic observation}

Mixed cultures (sludge) from batch reactor were investigated by cell staining procedures and by scanning electron microscopy (SEM) and transmission electron microscopy (TEM). Dual staining with DAPI and Nile Blue was performed for the detection of PHB. The sample was observed with a Carl Zeiss Axioplan epifluorescence microscope. The detail was described by Kawaharasaki et al. ${ }^{[24]}$ and Serafim et al. ${ }^{[25]}$. SEM (HITACHI S-3000N) and TEM (HITACHI H-7500) were preformed according to protocols described by DeneusMustin et al. ${ }^{[26]}$.

\subsection{Calculations}

The PHB content in the sludge was determined by:

$$
\operatorname{PHB}(\%)=\frac{\mathrm{PHB}}{\mathrm{MLSS}} \times 100(\mathrm{mg} / \mathrm{mg}) .
$$

The specific acetate uptake rate (Ac per $\mathrm{X} \cdot \mathrm{h},-q_{S}$ in $\mathrm{C}-\mathrm{mmol} / \mathrm{C}-\mathrm{mmol} \cdot \mathrm{h}$ ), specific $\mathrm{PHB}$ storage rate (PHB per $\mathrm{X} \cdot \mathrm{h}, q_{P}$ in $\left.\mathrm{C}-\mathrm{mmol} / \mathrm{C}-\mathrm{mmol} \cdot \mathrm{h}\right)$, the specific ammonia uptake rate ( $\mathrm{N}$ per $\mathrm{X} \cdot \mathrm{h},-q_{N}$ in $\left.\mathrm{N}-\mathrm{mmol} / \mathrm{C}-\mathrm{mmol} \cdot \mathrm{h}\right)$ and the yield of $\mathrm{PHB}$ (PHB per Ac, $Y_{\mathrm{P} / \mathrm{S}}$ in $\mathrm{C}-\mathrm{mmol} / \mathrm{C}-\mathrm{mmol}$ ) were calculated according to Serafim et al. ${ }^{[11]}$. The yield of active biomass (X per Ac, $Y_{\mathrm{X} / \mathrm{S}}$ in $\mathrm{C}-\mathrm{mmol} / \mathrm{C}-\mathrm{mmol}$ ) was calculated from the ammonia uptake considering the molecular formula for biomass $\mathrm{C}_{5} \mathrm{H}_{7} \mathrm{NO}_{2}: 8 \mathrm{mg}$ of bio- 
mass contains $1 \mathrm{mg}$ of $\mathrm{N}^{[27]}$. In experiments, it was assumed that all the ammonia was used for growth because nitrification was inhibited by thiourea.

\section{Results and discussion}

\subsection{SBR performance}

The objective of the SBR operation was to enrich the sludge with a high PHB storage potential. The PHB storage capacity of the inoculating sludge could be gradually increased under a dynamic feeding condition. Figures 1(a) and (b) showed a typical cycle behavior of acetate, PHB, SOUR, DO, $\mathrm{pH}$, and ammonia in the SBR. The observations in Figure 1(a) indicate that the cycle is clearly divided into two phases, i.e. the feast period (initial $40 \mathrm{~min}$ of the operation) and the famine period (after $40 \mathrm{~min}$ ). During the feast period, acetate was quickly removed and PHB content increased accordingly (Figure 1(a)). At the end of feast period, the PHB content of $21 \%$ in the sludge was obtained. In the same period, the DO decreased immediately to a minimum due to acetate consumption. At the same time, the SOUR increased to a very high level and lasted for initial $40 \mathrm{~min}$.
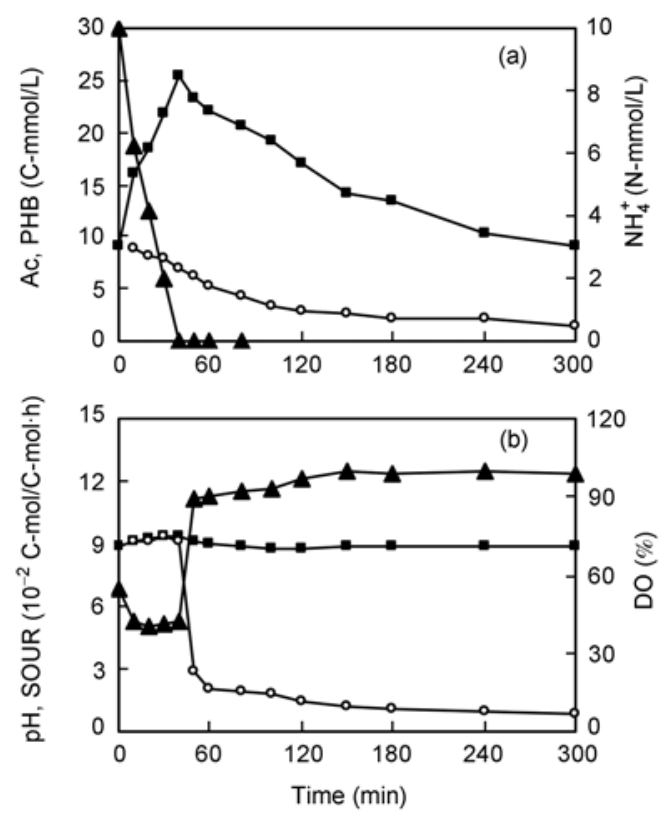

Figure 1 The typical SBR cycle during a SBR cycle under dynamic feeding regime. (a) The profile of acetate $(\boldsymbol{\Delta})$, PHB $(\boldsymbol{\bullet})$ and

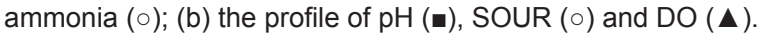

During the famine period, the PHB stored in the cell was consumed as energy and carbon resource, because of acetate exhaustion. The DO immediately increased and the SOUR decreased simultaneously. Therefore, the inflections in the profiles of DO and SOUR were a direct observation to define the transition of the feast to the famine period. The $\mathrm{pH}$ in the SBR was not controlled and fluctuated in the range of 8.8 to 9.5 in one cycle, as shown in Figure 1(b). Though ammonia concentration gradually decreased, it was still over $5 \mathrm{mg} / \mathrm{L}$ at the end of cycle. Therefore, ammonia was a no limiting factor in this test based on the result of the previous research $^{[28]}$.

These results indicate that the microorganisms with high PHB capacity storage can be enriched through the dynamic feeding regime in the SBR. In the following batch experiments, the process parameters in batch reactor were investigated for optimization of PHB production.

\subsection{Optimization of operating conditions effect of DO}

Figure 2 showed the results of acetate removal and PHB production under different $\mathrm{DO}$ concentrations in the batch reactors. The acetate removal rate and PHB storage rate obviously increased with the increase of DO concentration. Moreover, the maximum PHB production increased with the DO concentration, and was positive correlative with the removal rate of acetate, though the initial concentration of acetate was the same. For example, at the end of storage reaction, the PHB productions were $25 \mathrm{C}-\mathrm{mmol} / \mathrm{L}$ and $17 \mathrm{C}-\mathrm{mmol} / \mathrm{L}$, respectively, under the conditions of $70 \%$ and $10 \%$ of DO saturation (Figure 2).
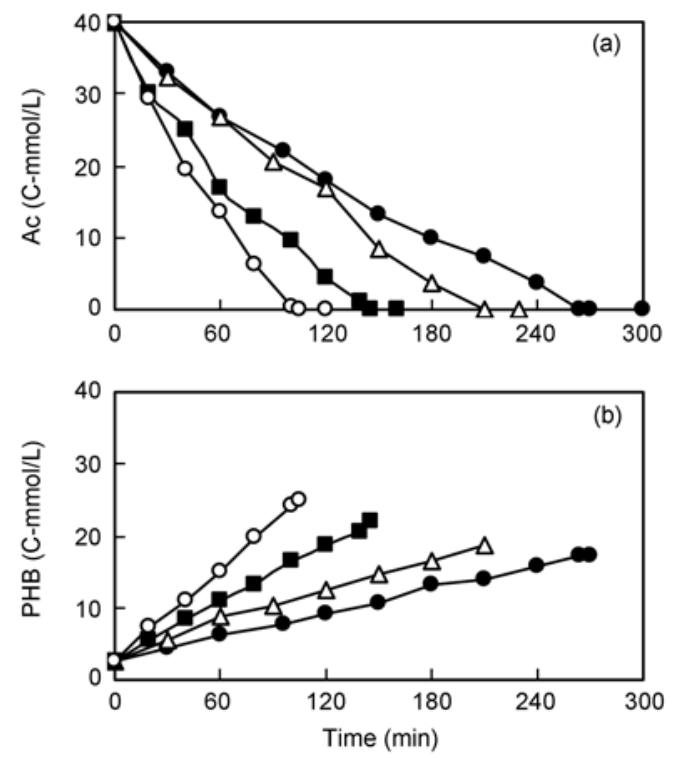

Figure 2 The profile of acetate consumption and PHB accumulation in the batch reactors with different DO • $10 \%$; $\triangle 20 \%$; $40 \%$; $\circ 70 \%$ of DO saturation. 
A previous literature reported that an oversupply of oxygen would result in a decrease of PHB yield because a higher proportion of acetate was converted into a biomass growth at higher DO concentration ${ }^{[29]}$. However, our research found that high DO concentration favored to enhance PHB content. As a result of the increased DO concentration, the increase of acetate uptake rate outclassed the increase of growth rate. Thus, the excess acetate had to be converted to PHB to maintain a balanced metabolism, which resulted in the enhanced PHB yield and content.

Enhanced DO concentration means that more electron acceptors are available for the production of energy by microorganisms in sludge. This consequently means that substrate uptake activity is enhanced due to the fact that the microorganisms cultivated in chemostat-like reactor always induce the maximal level of substrate uptake enzymes ${ }^{[30]}$. However, the growth rate is determined by the enzyme and RNA content for growth processes. Induction of these enzymes strongly depends on the previous growth condition of microorganisms ${ }^{[4]}$. On the other hand, the transport of acetate over the cell membrane is an energy required process ${ }^{[31]}$. Based on this condition, we postulate that enhanced DO concentration accelerates the uptake of acetate and then improves PHB storage.

(1) Effect of $\mathrm{pH}$

According to some related literatures, the experiments of PHB storage were usually carried out at $\mathrm{pH} 7.0$ or $\mathrm{pH}$ $7.5^{[14,32,33]}$. In order to evaluate the effect of $\mathrm{pH}$ on PHB production, a set of experiments were performed with $\mathrm{pH}$ control and compared with the one without $\mathrm{pH}$ control. The results were shown in Figure 3.

In the $\mathrm{pH}$ range of 7.0 to 10 , the PHB storage had no significant change regardless of $\mathrm{pH}$ control or un-control, and the similar PHB contents were obtained. This result indicated that the PHB metabolism was not sensitive to $\mathrm{pH}$ under the weak alkaline condition. However, the acetate uptake and PHB storage stopped when $\mathrm{pH}$ was controlled at 6.0 or 11 (the date was not shown). At $\mathrm{pH}$ of 6.0, the majority of acetate was in the form of undissociated weak acid, which would cross cell membranes and acidify the cytoplasm ${ }^{[34]}$. Thus, the PHB was not synthesized as a result of the acetate uptake inhibited. A similar phenomenon was observed by Bond et al. ${ }^{[35]}$. In their study, intracellular acidification of sludge inhibited PHB formation under a low $\mathrm{pH}$ condition in the enhanced biological phosphorus removal process. When
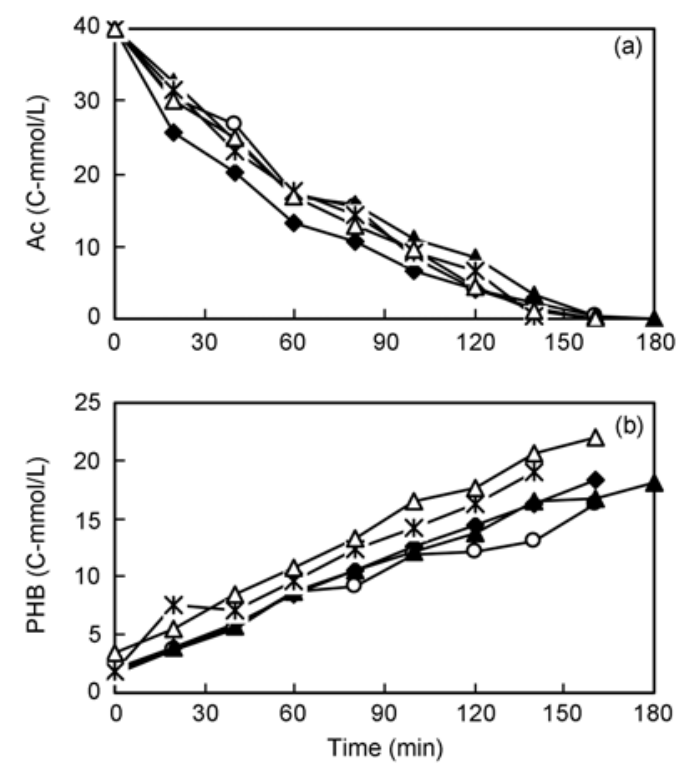

Figure 3 The profile of acetate consumption and PHB accumulation in the batch reactors with different $\mathrm{pH} \diamond 7.0$; $\circ 8.0 ; \quad \boldsymbol{\Delta} 9.0$; * 10; $\triangle$ un-control.

$\mathrm{pH}$ was controlled at 11 , it was reasonable to consider that the biological activity was inhibited completely by so high alkalinity.

Under aerobic conditions, the theoretical oxidation of acetate is as follows:

$$
\mathrm{CH}_{3} \mathrm{COO}^{-}+\mathrm{H}^{+}+2 \mathrm{O}_{2} \rightarrow 2 \mathrm{CO}_{2}+2 \mathrm{H}_{2} \mathrm{O} \text {. }
$$

Eq. (2) shows that the oxidation of acetate consumes hydrogen ions in a ratio of 1 mole to 1 mole, i.e. an increase in the solution $\mathrm{pH}$ is inevitable as acetate is oxidized. In this study, the $\mathrm{pH}$ in batch reactor increased from the initial value of 7.6-8.3 after acetate addition, and then maintained at a high level $(9.3-9.6)$ to the end of experiment under the condition without $\mathrm{pH}$ control. Moreover, the yield of PHB was slightly higher under $\mathrm{pH}$ un-control condition than those under $\mathrm{pH}$-control conditions. It was obvious that $\mathrm{pH}$ control was not necessary to improve PHB production, except for the case in which $\mathrm{pH}$ value was out of the range of 7.0 to 10 .

(2) Effect of $\mathrm{F} / \mathrm{M}$ ratio

The $\mathrm{F} / \mathrm{M}$ ratio is an important parameter affecting the biological reaction process. In the following experiments, the initial concentration of biomass was fixed and a different amount of acetate was added to obtain a different $\mathrm{F} / \mathrm{M}$ ratio. Thus, the different $\mathrm{F} / \mathrm{M}$ ratio was represented as the different initial concentrations of acetate in the batch reactors. Figure 4 showed the experimental results of the acetate removal and PHB production in the batch 
reactors with different $\mathrm{F} / \mathrm{M}$ ratios. The time used for acetate uptake increased with the initial concentration of acetate (Figure 4(a)), and the maximum PHB production increased correspondingly, excepting the $\mathrm{F} / \mathrm{M}$ ratio of 6.0 (Figure 4 (b)). The highest amount of PHB production and PHB content were $85 \mathrm{C}-\mathrm{mmol} / \mathrm{L}$ and $64 \%$, respectively, at the $\mathrm{F} / \mathrm{M}$ ratio of $4.5 \mathrm{C}-\mathrm{mmol} / \mathrm{C}-\mathrm{mmol}$.
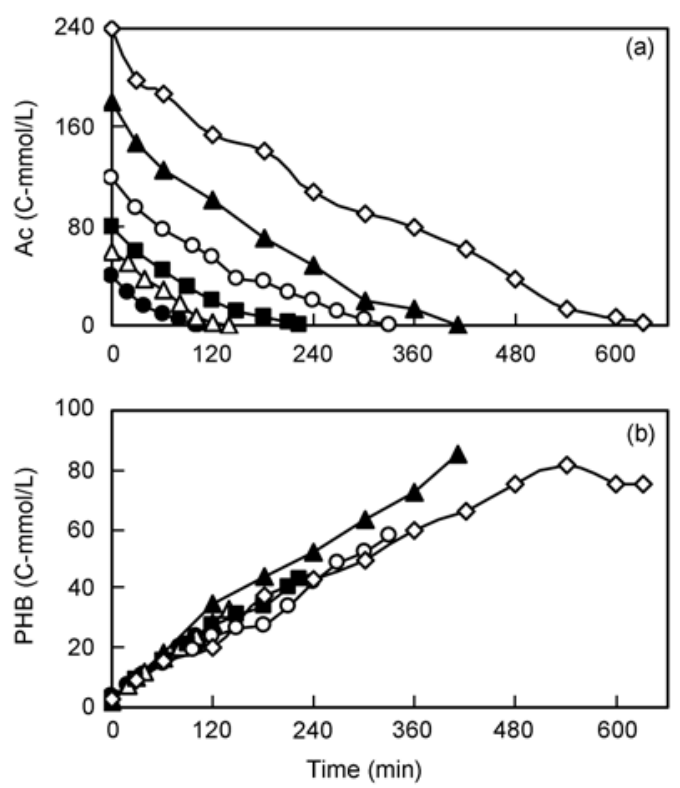

Figure 4 The profile of acetate consumption and PHB production in the batch reactors with different F/M ratios $\bullet 1.0 ; \triangle 1.5$; 2.0 ; $\circ 3.0 ; \Delta 4.5 ; \diamond 6.0 \mathrm{C}-\mathrm{mmol} / \mathrm{C}-\mathrm{mmol}$.

When $\mathrm{F} / \mathrm{M}$ ratio was $6.0 \mathrm{C}-\mathrm{mmol} / \mathrm{C}-\mathrm{mmol}$, the rates of acetate uptake and PHB storage decreased sharply. Serafim et al. ${ }^{[13]}$ speculated that high acetate concentration inhibited the metabolism of PHB storage. The PHB concentration began to decrease at 540 min after acetate addition, though acetate was not depleted at that time (Figure 4). This implied that the utilization of intracellular PHB and external substrate occurred simultaneously when the storage reaction proceeded for a long time. The phenomenon was not reported in previous literatures. Therefore, the selection of appropriate $\mathrm{F} / \mathrm{M}$ ratio is important for maximizing PHB content. If the substrate is oversupplied, e.g. F/M ratio above $4.5 \mathrm{C}-\mathrm{mmol} / \mathrm{C}-\mathrm{mmol}$, two negative effects occur. Firstly, too high substrate concentration inhibits the uptake of substrate, resulting in decreased PHB content. On the other hand, high F/M ratio results in the need of a longer time for acetate uptake (Figure 4).

(3) Analyse of operating conditions for high PHB production

The foregoing experimental data and calculated kinetic parameters were summarized in Table 2. Some tendencies can be found from these data. At a fixed F/M ratio of $1.0 \mathrm{C}-\mathrm{mmol} / \mathrm{C}-\mathrm{mmol}$, when the $\mathrm{DO}$ concentrations were increased to $70 \%$ from $10 \%$ of saturation, the specific uptake rate of acetate $\left(-q_{s}\right)$, specific storage rate of PHB $\left(q_{p}\right)$ and yield of PHB $\left(Y_{P}\right)$ all had an obvious increase, but the yield of active biomass $\left(Y_{X}\right)$ presented a little of decrease. Moreover, the PHB content increased clearly with DO concentration. When the DO concentration was fixed at $70 \%$ and the $\mathrm{F} / \mathrm{M}$ ratio was increased to 6.0 from $1.5 \mathrm{C}-\mathrm{mmol} / \mathrm{C}-\mathrm{mmol}$, an opposite result was obtained, which the $q_{s}, q_{p}$ and $Y_{P}$ had all decrease, whereas $Y_{X}$ increases. According to the experience of the effect of DO, the PHB content should be decreased here. However, the PHB content stored in the sludge in-

Table 2 Typical kinetic and stoichiometric parameters for the experiments with different operational conditions

\begin{tabular}{|c|c|c|c|c|c|c|c|c|c|}
\hline $\mathrm{DO}(\%)$ & $\mathrm{pH}$ & $\mathrm{F} / \mathrm{M}$ & $C$ & $N$ & $-q_{s}$ & $q_{P}$ & $Y_{X}$ & $Y_{P}$ & PHB (\%) \\
\hline 10 & uncontrol & 1.0 & 40 & 1.5 & $0.19(0.021)$ & $0.07(0.010)$ & 0.14 & 0.36 & 26 \\
\hline 20 & uncontrol & 1.0 & 40 & 1.5 & $0.26(0.036)$ & $0.10(0.007)$ & 0.13 & 0.41 & 30 \\
\hline 40 & uncontrol & 1.0 & 40 & 1.5 & $0.34(0.020)$ & $0.16(0.024)$ & 0.11 & 0.48 & 33 \\
\hline 70 & uncontrol & 1.0 & 40 & 1.5 & $0.56(0.031)$ & $0.30(0.006)$ & 0.11 & 0.56 & 37 \\
\hline 40 & 7 & 1.0 & 40 & 1.5 & $0.40(0.010)$ & $0.16(0.030)$ & 0.11 & 0.40 & 32 \\
\hline 40 & 8 & 1.0 & 40 & 1.5 & $0.41(0.021)$ & $0.14(0.017)$ & 0.10 & 0.37 & 31 \\
\hline 40 & 9 & 1.0 & 40 & 1.5 & $0.40(0.020)$ & $0.17(0.028)$ & 0.15 & 0.41 & 32 \\
\hline 40 & 10 & 1.0 & 40 & 1.5 & $0.42(0.008)$ & $0.17(0.034)$ & 0.10 & 0.43 & 32 \\
\hline 70 & uncontrol & 1.5 & 60 & 2.25 & $0.68(0.006)$ & $0.34(0.007)$ & 0.09 & 0.51 & 44 \\
\hline 70 & uncontrol & 2.0 & 80 & 3.0 & $0.67(0.001)$ & $0.34(0.019)$ & 0.10 & 0.51 & 53 \\
\hline 70 & uncontrol & 3.0 & 120 & 4.5 & $0.63(0.031)$ & $0.29(0.029)$ & 0.13 & 0.46 & 57 \\
\hline 70 & uncontrol & 4.5 & 180 & 6.75 & $0.61(0.029)$ & $0.28(0.039)$ & 0.13 & 0.46 & 64 \\
\hline 70 & uncontrol & 6.0 & 240 & 9.0 & $0.46(0.017)$ & $0.14(0.041)$ & 0.16 & 0.30 & 40 \\
\hline
\end{tabular}

The values in parentheses are the standard deviation; DO in \% of air saturation; F/M ratio in C-mmol C-mmol ${ }^{-1} ; C$ in $\mathrm{C}-\mathrm{mmol} \mathrm{L}^{-1} ; N$ in $\mathrm{N}-\mathrm{mmol} \mathrm{L}^{-1} ;-q_{S}$ in C-mmol C-mmol ${ }^{-1} \mathrm{~h}^{-1} ; q_{P}$ in C-mmol C-mmol ${ }^{-1} \mathrm{~h}^{-1} ; Y_{X}$ in C-mmol C-mmol ${ }^{-1} ; Y_{P}$ in C-mmol C-mmol ${ }^{-1}$. 


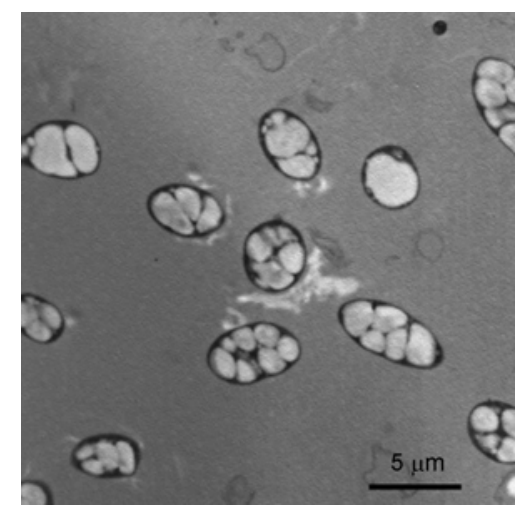

Figure 5 SEM image of the coccus-shap morphology of the cells, Bar is $5 \mu \mathrm{m}$.

creased significantly with the increase of $\mathrm{F} / \mathrm{M}$ ratio from 1.5 to $4.5 \mathrm{C}-\mathrm{mmol} / \mathrm{C}-\mathrm{mmol}$, the highest PHB content of $64 \%$ was obtained at the $\mathrm{F} / \mathrm{M}$ ratio of $4.5 \mathrm{C}-\mathrm{mmol} /$ $\mathrm{C}-\mathrm{mmol}$, but it decreased at $6.0 \mathrm{C}-\mathrm{mmol} / \mathrm{C}-\mathrm{mmol}$. The reasons why the $\mathrm{PHB}$ content was lower at $\mathrm{F} / \mathrm{M}$ ratio of 1.5-3.0C-mmol/C-mmol than $4.5 \mathrm{C}-\mathrm{mmol} / \mathrm{C}-\mathrm{mmol}$ was likely to substrate limitation. It can be confirmed by the experimental results in Figure 5.

\subsection{Microscopic observation}

Microscopic observation was performed, and the sludge collected from the batch reactor with the $\mathrm{F} / \mathrm{M}$ ratio of 4.5C-mmol/C-mmol. The SEM images in Figure 5 showed that the cells in sludge had a considerable homogeneous morphology. Almost all of the cells were cocci that occur singly or in packed. Few short-rod shape cells were observed. The typical length of a single cell varied from 1 to $2 \mu \mathrm{m}$. Abundant intracellular granules were observed (Figure 6). These accumulated cellular granules stained positively with PHB dye (Figure

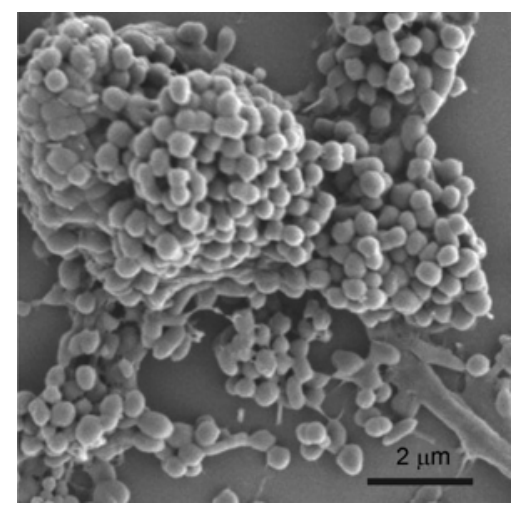

Figure 6 TEM image the present of intracellular PHB granules, Bar is $2 \mu \mathrm{m}$.

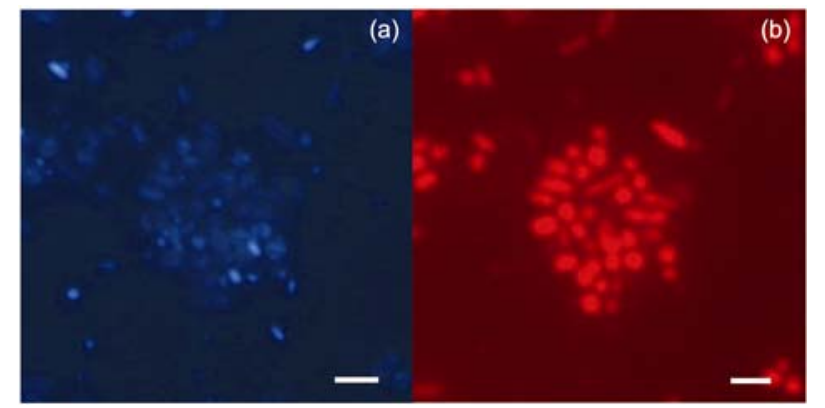

Figure 7 Fluorescence micrographs of dual staining with DAPI and Nile Blue. (a) The sludge stained with DAPI. Blue fluorescence means all cells; (b) the sludge stained with Nile Blue at identical microscopic field as in (a). Red fluorescence means the cells with PHB granules. Bar is $2 \mu \mathrm{m}$ for (a) and (b).

7(b)), and further confirmed to be PHB by gas chromatography. Dual staining with DAPI and Nile Blue revealed the presence of PHB inclusions in almost all of the cells (Figure 7). The electron micrographes clearly confirmed that the microorganisms with storage ability were effectively selected and enriched in SBR reactor, and a large amount of PHB was stored in the batch reactor.

The microscopic observation confirmedly supported the experimental data. Though the evolution of microbial population structure was not included in this study, it can be concluded that the microorganisms with the ability to store PHB were the dominant population in system.

\section{Conclusion}

The DO concentration and $\mathrm{F} / \mathrm{M}$ ratio have a strong effect to $\mathrm{PHB}$ content stored in sludge. However, the $\mathrm{pH}$ value is not an important factor on PHB production in the range of 7 to 10. The PHB content increases with DO concentration. An opportune $\mathrm{F} / \mathrm{M}$ ratio is crucial to obtain the highest PHB content. The DO of $70 \%$ and $\mathrm{F} / \mathrm{M}$ ratio of $4.5 \mathrm{C}-\mathrm{mmol} / \mathrm{C}-\mathrm{mmol}$ are suggested as optimum parameters of $\mathrm{PHB}$ production by the activated sludge.

The PHB content of $64 \%$ achieved in this study was close to those of pure culture microorganisms and was considerablely high comparing with those of activated sludge (Table 1). Especially, it should be pointed out that the PHB production by the activated sludge in this study without growth limitation is caused by nutrient element insufficiency, which was substantially significant for PHB production by reusing the organic waste. 
1 Khanna S, Srivastava A K. Recent advances in microbial polyhydroxyalkanoates. Process Biochem, 2005, 40: 607-619

2 Lee S Y, Choi J, Wong H H. Recent advances in polyhydroxyalkanoate production by bacterial fermentation: Mini-review. Int J Biol Macromol, 1999, 25: 31-36

3 Lee S Y. Plastic bacterial? Progress and prospects for polyhydroxyalkanoate production in bacteria. Trends Biotechnol, 1996, 14: $431-438$

4 Reis M A M, Serafim L S, Lemos P C, et al. Production of polyhydroxyalkanoates by mixed microbial cultures. Bioprocess Biosyst Eng, 2003, 25: $377-385$

5 Salehizadeh $\mathrm{H}$, van Loosdrecht M C M. Production of polyhydroxyalkanoates by mixed culture: Recent trends and biotechnological importance. Biotechnol Adv, 2004, 22: 261 - 279

6 Satoh H, Iwamoto Y, Mino T, et al. Activated sludge as a possible source of biodegradable plastic. Water Sci Technol, 1998, 38: $103-109$

7 Chua A S M, Takabatake H, Satoh H, et al. Production of polyhydroxyalkanoates (PHA) by activated sludge treating municipal wastewater: Effect of $\mathrm{pH}$, sludge retention time (SRT) and acetate concentration in influent. Water Res, 2003, 37: 3602-3611

8 Beun, J J, Dircks K, van Loosdrecht M C M, et al. Poly- $\beta$-hydroxybutyrate metabolism in dynamically fed mixed microbial cultures. Water Res, 2006, 36: 1167-1180

9 Dionisi D, Majone M, Tandoi V, et al. Sequencing batch reactor: Influence of periodic operation on performance of activated sludges in biological wastewater treatment. Ind Eng Chem Res, 2001, 40: 5110-5119

10 Majone M, Dircks K, Beun J J. Aerobic storage under dynamic conditions in activated sludge processes. The state of the art. Water Sci Technol, 1999, 39: 61-73

11 van Loosdrecht M C M, Pot M A, Heijnen J J. Importance of bacterial storage polymers in bioprocesses. Water Sci Technol, 1997, 35: 41-47

12 Lemos P C, Serafim L S, Reis M A M. Synthesis of polyhydroxyalkanoates from different short- chain fatty acids by mixed cultures submitted to aerobic dynamic feeding. J Biotechnol, 2006, 122: $226-238$

13 Serafim L S, Lemos P C, Oliveira R, et al. Optimization of polyhydroxybutyrate production by mixed cultures submitted to aerobic dynamic feeding conditions. Biotechnol Bioeng, 2004, 87: 145-160

14 Dionisi D, Majone M, Papa V, et al. Biodegradable polymers from organic acids by using activated sludge enriched by aerobic periodic feeding. Biotechnol Bioeng, 2004, 85: 569-579

15 Yamane T, Fukunaga M, Lee Y W. Increased PHB roductivity by high-cell-density fed-batch culture of alcaligenes latus, a growthassociated PHB producer. Biotechnol Bioeng, 1996, 50: 197-202

16 Ryu H W, Hahn S K, Chang Y K, et al. Production of poly(3-hydroxybutyrate) by high cell density fed-batch culture of alcaligenes eutrophuswith phosphate limitation. Biotechnol Bioeng, 1997, 55: $28-32$

17 Du G C, Yu J. Green technology for conversion of food scraps to biodegradable thermoplastic polyhydroxyalkanoates. Environ Sci Technol, 2002, 36: 5511-5516

18 Taguchi S, Nakamura H, Kichise T, et al. Production of polyhydroxyalkanoate (PHA) from renewable carbon sources in recombinant Ralstonia eutropha using mutants of original PHA synthase. Biochem En, 2003, 16: 107-113
19 Wang F, Lee S Y. Production of poly (3-hydroxybutyrate) by fedbatch culture of filamentation-suppressed recombinant escherichia coli. Appl Environ Microbiol, 1997, 63: 4765-4769

20 Smolder G J F, van der Meij J, van Loosdretch M C M, et al. Model of the anaerobic metabolism of the biological phosphorus removal process: Stoichiometry and $\mathrm{pH}$ influence. Biotechnol Bioeng, 1994, 44: $461-470$

21 APHA. Standard Methods for Examination of Water and Wastewater, 20th ed. Washington. D.C.: American Public Health Association, 1998

22 Baetens D, Aurola A M, Foglia A, et al. Gas chromatographic analysis of polyhydroxybutyrate in activated sludge: A round-robin test. Water Sci Technol, 2002, 46: 357-361

23 Braunegg G, Sonnleitner B, Lafferty R M. A rapid gas chromatographic method for the determination of poly- $\beta$-hydroxybutyric acid in microbial biomass. Eur J App Microbio Biotechnol, 1978, 6: $29-37$

24 Kawaharasaki M, Tanaka H, Kanagawa T, et al. In site identification of polyphosphate-accumulating bacteria in activated sludge by dual staining with $r$ RNA-targeted oligonucleotide probes and 4, 6-Diamidino-2-Phenylindol (DAPI) at a polyphosphate-probing concentration. Water Res, 1999, 33: 257-265

25 Serafim L S, Lemos .P C, Levantesi C, et al. Methods for detection and visualization of intracellular polymers stored by polyphosphate-accumulating microorganisms. J Microbiol Methods, 2002, 51: $1-18$

26 Deneux-Mustin S, Lartiges B S, Villemin G, et al. Ferric chloride and lime conditioning of activated sludges: An electron microscopic study on resin-embedded samples. Water Res, 2001, 35: 3018-3024

27 Henze M, Harremoës P, LaCour Jansen J, et al. Wastewater treatment: Biological and chemical processes. New York: Springer, 2000

28 Jenkins D, Richard M D, Daigger G T. Manual on The Causes and Control of Activated Sludge Bulking, Foaming, and Other Solids Separation Problems. 3th ed. Boca Raton: CRC Press LLC, 2004

29 Third K A, Newland M, Cord-Ruwisch R. The effect of dissolved oxygen on PHB accumulation in activated sludge cultures. Biotechnol Bioeng, 2003, 82: 238-250

30 van Aalst-van Leeuwen M A, Pot M A, Van Loosdrecht M C M. Kinetic modeling of poly(-hydroxybutyrate) production and consumption by Paracoccus pantotrophus under dynamic substrate supply. Biotechnol Bioeng, 1997, 55: 773-782

31 Smolder G J F, van der Meij J, van Loosdretch M C M, et al. Stoichiometric model of the aerobic metabolism of the biological phosphorus removal process. BiotechnolBioeng, 1994, 44: 837-848

32 Beun J J, Paletta F, van Loosdrecht M C M, et al. Stoichiometry and kinetics of poly-hydroxybutyrate metabolism in aerobic, slow growing, activated sludge cultures. Biotechnol Bioeng, 2000, 67: 379389

33 Krishna C, van Loosdrecht M C M. Substrate flux into storage and growth in relating to activated sludge modeling. Water Res, 1999, 33: 3149-3161

34 Jones D T, Woods D R. Acetone-Butanol fermentation revisited. Microbiol Rev, 1986, 50: 484-524

35 Bond P L, Keller J, Blackall L L. Anaerobic phosphate release from activated sludge with enhanced biological phosphorus removal. A possible mechanism of intracellular $\mathrm{pH}$ control. Biotechnol Bioeng, 1999, 63: $507-515$ 